\title{
Influence of Hybrid Cooling-Lubricating Strategy in the Turning of ASTM F2063 Austenitic Nickel-Titanium Alloy
}

\author{
A.N. Mohd Khalila, A.I. Azmia,*, M.N. Murada, M.A. Mahboob Alia \\ ${ }^{a}$ Faculty of Mechanical Engineering Technology, Universiti Malaysia Perlis, Pauh Putra Campus, 02600 Arau, Perlis, \\ Malaysia.
}

Keywords:

Hybrid cooling

Lubricant

Nanolubricant

Nickel Titanium

Machining

* Corresponding author:

Azwan Iskandar Azmi

azwaniskandar@unimap.edu.my

Received: 16 November 2020

Revised: 20 December 2020

Accepted: 8 February 2021

\begin{abstract}
A B S T R A C T
Conventional machining of nickel-titanium shape-memory alloys (NiTi SMAs) faces significant challenges as a result of high thermal and mechanical distortions. The phase transformation temperatures of NiTi SMAs are primarily affected by the rise in temperature during the cutting process, which causes poor machinability under the conventional coolant approach. This research explored the effects of hybrid cooling-lubricating of minimal quantity nano-lubricants with compressible-chilled air generated from a vortex tube during the turning of the NiTi alloys. The experimental procedure involved measurement of induced-cutting force components under variable cutting conditions utilising various coolant approaches. A depth of cut, 0.5 $\mathrm{mm}$ with cutting speeds of 12.5, 25, and $50 \mathrm{~m} / \mathrm{min}$ and feed rates of 0.05 and $0.1 \mathrm{rev} / \mathrm{min}$ were utilised. The hybrid cooling approach of minimum quantity nano-lubricants with vortex cooling, can increase tool life for most of the tested conditions and has a considerable influence in reducing the inducedcutting force. In contrast, only marginal improvement was observed for the surface roughness when using the same coolant-lubricant strategy.
\end{abstract}

(C) 2021 Published by Faculty of Engineering

\section{INTRODUCTION}

Metalworking fluids (MWFs) are important in machining process as a way to transfer the heat accumulated at the interface of tool-flank face and deformed chip. The functions of MWFs are for lubrication, flushing the generated chips, and protecting the surface from any machining induced damage. Presently, the flood-coolant technique has been the preferred practice among all metal cutting industries to accomplish these purposes. However, environmental concerns, lack of efficient use, high pumping power requirements, high recycling and coolant disposal costs, and operator health risks are among the issues relating to flood-coolant approach. Report has shown that major health issues among machine operators accounted for approximately $80 \%$ of the occupational health disease and they are caused by the direct exposure to the MWFs. Furthermore, close to about $20 \%$ of the manufacturing costs is attributed by the applications of the MWFs [1]. 
Dry cutting is an environmental-friendly approach to provide cooling in the machining environment with risk-free environment to the machine operators. However, it contributes to poor machinability responses, particularly for hard-to-cut metal alloys. In fact, it is highly challenging to achieve the required end product quality when using hard-to-cut materials, especially for superalloys [2,3]. Dry machining environment often accelerate the deterioration of tool sharpness which shorten the lifespan of the cutting tool. This in turn leads to poor machined surface due to insufficient cooling and lubrication. Further improvement of coolinglubricating in the metal cutting environment has been achieved through minimum quantity lubrication (MQL) process and it has been widely adopted by metal cutting industries worldwide. The MQL approach, also known as near dry cutting or the mist-cooling method applies a small amount of fluid to the machining environment. Yildirim et al. reported that MQL only uses a small volume of lubricant in the form of tiny liquid droplets $(\sim 10-100 \mathrm{~mL} / \mathrm{h})[4,5]$. The machinability efficiency of this approach increases significantly as the lubricant penetrates close to the cutting zone. Furthermore, Yildirim explained that during machining, most of the cutting fluid can be vaporised, thereby preventing any harm to the worker health as well as the environment [4].

However, the chip removal efficiency with the heat and friction generated hinder the MQL performance; particularly for heavy cutting environments experienced with hard-to-cut metal alloys, due to the aforementioned vaporisation. Numerous studies have resolved the insufficient cooling effect of MQL by the suspension of nanoparticles in the MQL cutting fluids $[5,6]$. Suspended-nanoparticles in the based-cutting fluids provided exceptional thermal conductivity with excellent tribological properties such as anti-friction functions, antiwear characteristics, and bearing capacities [7]. Dambatta et al. claimed that the application silicon dioxide-suspended-nanoparticles in the MQL system had a significant influence towards the reduction of grinding wheel wear and forces, that improved the workpiece surface roughness and surface damage [8]. The authors explained enhanced slewing action during material removal process was attributed by the formation of thin tribo-film on the ground surface [8].
A recent work by Yildirim et al. reported that a minimum amount of wear was achieved using a minimum quantity nano-lubricant (MQNL) containing 0.5 vol\% hexagonal boron nitride nanoparticles [9]. 43\% reduction of wear was achieved through this MQNL approach as compared to that of dry condition. The authors reasoned that both pressure and friction were alleviated as the added nanoparticles form an oil layer between the tool and the workpiece [9]. It was also conjectured that melting of metal during cutting was less effected due to the hexagonal crystalline structure of the nanoparticles as well as their chemical stability and high melting temperature. Meanwhile, Boswell et al. reviewed and found inconsistent results utilising MQNLs while machining difficult-to-cut materials [10] because of unsatisfactory effects of the cooling and heat transfer using compressed air $[7,10]$. With this regard, Kaynak asserted [4,12] that cryogenic cooling can help improve the surface quality and tool wear resistance and has substantial effects on the phase transformation behaviour of machined nickel-titanium shapememory alloys. Nonetheless, the cryogenic cooling remains unrealistic for wide-scale industrial applications due to the unnecessary cost and technical implications.

A recent approach, namely; the chilledcompressed air that is produced from a vortex tube, offers an innovative and cost-effective solutions. Report has shown that the vortex tube mechanically generates compressed-air that significantly decreases the air temperature to below $0{ }^{\circ} \mathrm{C}$. One of the benefits of vortex tube is that it does not involve any moving parts, without any chemical or electricity applications and only minimum parts maintenance is required [10]. Initial setup for Vortex tube cooling was considered feasible compared with the cryogenic due to the higher cost for the initial early machining setup [13] apart from its practical commercial applicability [14]. In fact, there are a few restrictions that are linked to cryogenics cooling method: i.e.; cryogenic creates insulating liquid nitrogen layer at high temperature which reduces the cooling efficiency. Furthermore, there is a dimensional inaccuracy on the work material due to extreme temperature difference that alter the subsurface damage of the work material [15]. Inarguably, it has been agreed among a number of researchers that cryogenic $\left(\mathrm{LN}_{2}\right.$ and $\left.\mathrm{CO}_{2}\right)$ cooling enables the extension in 
the tool useful life, hence, it improves machinability of the nickel titanium shape memory alloy $[4,15]$, and titanium alloy $[16,17]$. However, the improvement achieved in the machinability performance using chilledcompressed air is less than that achieved using the hybrid cooling approach, which is a combination of two cooling or lubricating approaches. The innovativeness and effectiveness of this approach have been disclosed by several researchers so as to impart improvement of lubrication and coolant effects for machining environment [12-14]. Nonetheless, limited number of studies have been reported on the machining of NiTi SMAs utilising MQNLs and hybrid cooling by a vortex tube.

NiTi SMAs have the unique ability to recover their original shape after deformation. Studies have proved that the unique shape-memory behaviour results from a phase change in the material from soft martensite to hard austenite due to the phase transformation temperature in the material properties [21]. NiTi SMAs are a smart and widely used material in diverse industries, including biomedicine, aerospace, and automotive. Due to the aforementioned peculiar behaviours, various issues and challenges are confronted by researchers and industrial practices during the shaping and processing of $\mathrm{NiTi}$ alloys and this includes the machining and cutting. Numerous studies have reported that conventional machining techniques on the hardto-cut alloys leads to premature failure of cutting tool due to accelerated tool wear if undesirable cutting conditions and parameters conditions are employed. Very often, the conventional machining processes contribute to elevated thermal and mechanical stresses that significantly influence the shape-memory behaviour of these alloys [22].

A previous study have shown that different types of coolant environment approaches are used to machine hard-to-cut materials; therefore, the selection of a suitable coolant approach in the machining technique for machining NiTi SMAs needs to be identified to improve product performance [11]. With this regard, the feasibility of applying hybrid cooling utilising MQNL with vortex environments for turning NiTi SMA F2063 is yet attempted by previous researchers [11]. It is worth to mention that the ASTM F2063 is the standard that specifies the requirements for NiTi alloys to be used as medical devices. The standard prescribes the chemical compositions, mechanical properties, super-elastic characteristics, grain size, and metamorphic temperature [23]. In this study, turning experiments were conducted on ASTM F2063 NiTi SMA that evaluated the cutting force, tool wear, and wear mechanism under dry, MQL, MQNL with nano-environments and MQNL with vortex tube-generated chilled-compressed air (MQNL Vortex) at varying cutting velocities, feed rates, and constant depth of cut conditions, respectively. The novelty of the study is the comprehensive study of cooling combination techniques of the MQNL with and MQNL with vortex tube-generated chilled-compressed air (MQNL Vortex) in the turning of NiTi SMA F2063.

\section{EXPERIMENTAL METHOD}

\subsection{Nano-lubricant and material preparation}

Preparation of the nano-lubricants was through a two-step method with sonication technique. This experiment employed the aluminum oxide particles due to their cost-effectiveness and extensive use in engineering ceramics [24]. The nanoparticles were suspended in the SolCut oil (base oil) to attain a nano-lubricant solution. A specific portion of surfactant (1\%), Sodium dodecylbenzene sulfonate (SDBS) was added to the nano-lubricant to inhibit any potential of the nanoparticles to agglomerate [19]. The sonication process was performed for at least 3 hours to ensure a complete homogenisation of the $\mathrm{Al}_{2} \mathrm{O}_{3}$ nanoparticles and SDBS within the SolCut oil.

\subsection{Workpiece details}

Machining workpiece was a NiTi alloy that has a $49.3 \% \mathrm{Ni}$ and $50.7 \% \mathrm{Ti}$ elements. The phase transformation study conducted on the NiTi has confirmed that the alloy was in the austenite phase at the room temperature, Figure 1. This differential scanning calorimetry (DSC) characterisation was conducted at $10^{\circ} \mathrm{C} / \mathrm{min}$ heating and cooling rate using a Perkin Elmer DSC machine. Based on Figure 1, the martensite start and finish temperatures were 4.65, -12.25, whereas the austenite start, As and austenite finish, Af temperatures were 18.97, and $33.81^{\circ} \mathrm{C}$, respectively. Phase 
transformation is an essential criterion for this shape memory alloy since it governed the alloy's super-elasticity and shape-memory effects. It is important to highlight that selection of the NiTi alloy is governed by the working temperature, namely the austenite and martensite temperatures [26].

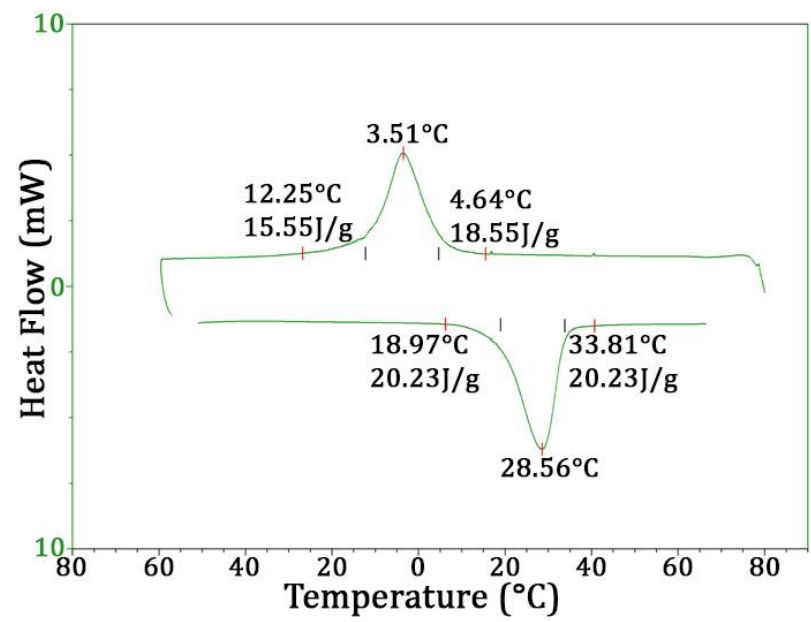

Fig. 1. Transformation phase result by using differential scanning calorimetry for the nickeltitanium alloy workpiece.

\subsection{Experimental setup and parameters}

Chevalier FCL-608 CNC turning machine was used for the experimental trials. The coated carbide of roughing type cutting inserts were supplied by SECO Tools Sdn. Bhd. These inserts have a $0.8 \mathrm{~mm}$ nose radius. The MQL supply was set with $0.6 \mathrm{MPa}$ pressure so that it supplied a flow rate of $40 \mathrm{~mL} / \mathrm{h}$ for the nanolubricants. Temperature of $-12^{\circ} \mathrm{C}$ with a tolerance of $\pm 5^{\circ} \mathrm{C}$ was achieved at the air outlet of the vortex tube system. Table 1 and Figure 2 outlined the experimental setups and machining conditions as well as parameters. The growth of wear on cutting insert was consistently observed on the XOPTRON Stereo Microscope XST60. The wear characterisation was processed using the iSolution Lite software on the images of the insert captured by the microscope. The maximum flank wear length, VBmax of $0.3 \mathrm{~mm}$ was chosen as the limit or criteria for the tool to reach it useful life. A three-component type dynamometer (model KISTLER 9129AA) was employed to acquire the machining force signals during the cutting process. The acquisition of force signals or data was carried out at a sampling frequency of 2 $\mathrm{kHz}$ using Kistler 9070 charge amplifier module and Dynoware software. The overall machining conditions and parameters are detailed out in Table 2. Meanwhile, the surface roughness average (Ra) was measured according to the ISO 4287 standard $[20,21]$ using a Handysurf E-35B portable surface roughness measurer. Measurements were repeated three times at three angles on the cylindrical workpiece surface $\left(0^{\circ}, 120^{\circ}\right.$, and $240^{\circ}$ ).

Table 1. Experimental and machine setup.

\begin{tabular}{|l|l|}
\hline \multicolumn{1}{|c|}{ Items } & \multicolumn{1}{|c|}{ Description } \\
\hline Machine Tool & $\begin{array}{l}\text { CHEVALIER FCL-608 CNC Turning } \\
\text { Machine }\end{array}$ \\
\hline $\begin{array}{l}\text { Working } \\
\text { material }\end{array}$ & Niti SMA \\
\hline $\begin{array}{l}\text { Cutting tool } \\
\text { (insert) }\end{array}$ & $\begin{array}{l}\text { SECO Roughing coated carbide insert } \\
\text { (nose radius: } 0.8 \mathrm{~mm}) \text { TNMG160408- } \\
\text { MR4 }\end{array}$ \\
\hline MQL supply & $\begin{array}{l}6.0 \text { bar, lubricant: } 40 \text { ml/h (through } \\
\text { external nozzle) MQL nanolubricants } \\
(<50 \text { nm) with SDBS }\end{array}$ \\
\hline Air Environment & $\begin{array}{l}\text { Vortex tube air outlet temperature, }-12 \\
{ }^{\circ} \mathrm{C}\left(+/-5{ }^{\circ} \mathrm{C}\right)\end{array}$ \\
\hline $\begin{array}{l}\text { Vortex tube } \\
\text { system }\end{array}$ & $\begin{array}{l}\text { Meech } 2400 \mathrm{Btu} / \mathrm{h} 35 \mathrm{cfm} \text { Pneumatic } \\
\text { Cold Fraction Vortex Tube Kit, } 8 \text { bar, }-60 \\
\rightarrow+110^{\circ} \mathrm{C}\end{array}$ \\
\hline
\end{tabular}

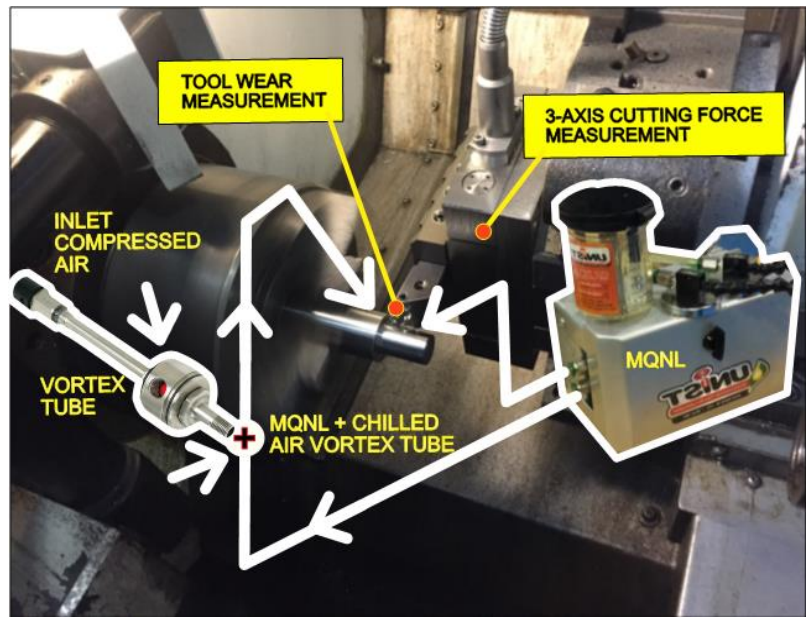

Fig. 2. Machining process and measurement setup.

Table 2. Cutting conditions and parameters.

\begin{tabular}{|l|c|c|c|}
\hline $\begin{array}{c}\text { Experimental } \\
\text { conditions }\end{array}$ & $\begin{array}{c}\text { Cutting } \\
\text { Speed, } \\
\text { Vc (m/min) }\end{array}$ & $\begin{array}{c}\text { Feed Rate, } \\
\mathbf{f}(\mathbf{m m} / \mathbf{r e v})\end{array}$ & $\begin{array}{c}\text { Depth of Cut, } \\
\text { ap (mm) }\end{array}$ \\
\hline $\begin{array}{l}\text { 1.Dry Cut } \\
\text { 2. } M Q L\end{array}$ & $\begin{array}{c}12.5,25 \text { and } \\
50\end{array}$ & 0.05 and 0.1 & 0.5 \\
3.MQNL & & & \\
4. $M Q N L$ vortex & & \\
\hline
\end{tabular}




\section{RESULTS AND DISCUSSION}

\subsection{Effect of machining parameters on machining force components over total cutting time}

Figure 4 shows that the MQNL vortex, produced promising results in alleviating the cutting forces at different cutting speeds and feed rates over the total cutting time. This approach was able to sustain the lowest cutting forces among all other approaches for most of the cutting parameters employed despite the fluctuation in the magnitude of cutting force and the increase in the cutting speed and feed rate. It is apparent that the presence of $\mathrm{Al}_{2} \mathrm{O}_{3}$ nanoparticle has assisted in retaining the oil molecule and prevented the immediate release of based fluids from the machining zone and yielded superior performance in terms of lubrication [29-30]. The small particle size of $\mathrm{Al}_{2} \mathrm{O}_{3}$ in base fluid increases the surface area relative to volume which gives the uniform distribution of particles and helps to enhance thermal conductivity and improves the effectiveness of Brownian motion [31]. Meanwhile, as asserted by Ali et al. and Sen et al. $[7,29]$, the addition of SDBS surfactant in the MQNL was able to alter the chemical properties of the based oil chemical which also attributed to the changes in the thermal conductivity of the lubricants. Likewise, the vortex cooling improved the heat conductivity to further bring down the magnitude of cutting forces. It is worth to highlight that the dry cutting approach exhibited a lower cutting force at the early stage of cutting duration compared to that of the other coolantlubricants approaches due to the initial sharpness of the tool insert. However, as the tool sharpness starts to deteriorate, the magnitudes of cutting force increased significantly with the cutting duration and are among the highest compared to all coolant-lubricants approaches.

As depicted in Figure $4 \mathrm{e}$ and $4 \mathrm{f}$, the graph pattern for the MQNL vortex took a slight dip between 16-22 min due to inconsistent contact between the cutting tool and workpiece. The accumulation of chips in the cutting zone might also prevented the effective cutting of the NiTi alloys which contributed towards the anomaly in the cutting force readings. Nevertheless, the cutting force pattern showed a sharp increased afterward (above $24 \mathrm{~min}$ ) as the tool was approaching the allowable wear limit. Based on the overall cutting force graphs shown in Figure 4, the combination of MQNL and vortex cooling reduced the cutting force due to the tribo-film on the surface between the cutting tool and workpiece as well as the higher cutting zone temperature. The film would lessen the friction between the cutting tool and workpiece to lower the induced-cutting force. Similar results were obtained by Chetan et al. [32] when they implemented a hybrid coolantlubricant of MQNL and liquid nitrogen in their experiment for machining nickel based Nimonic 90 alloy.

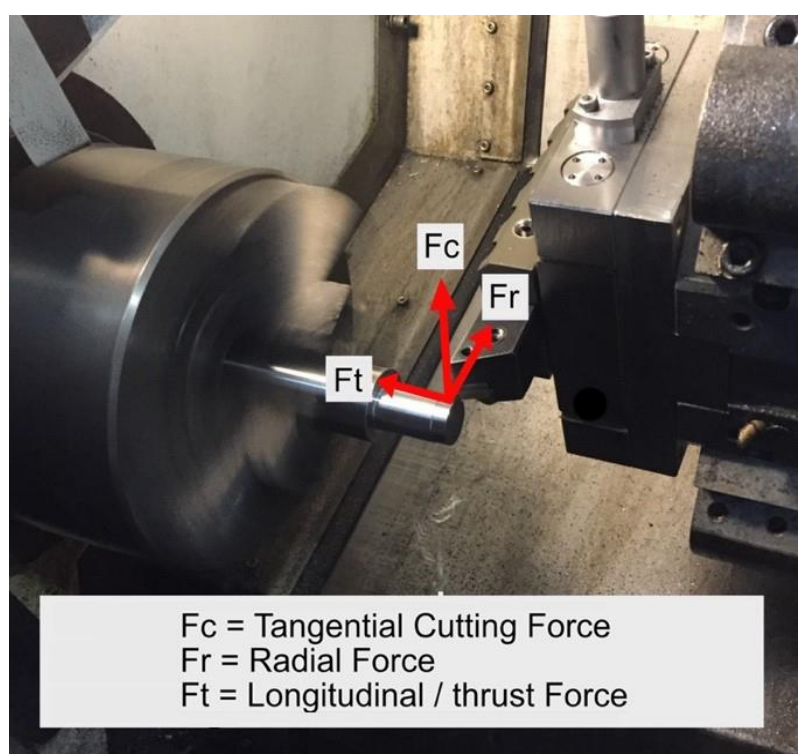

Fig. 3. Force action on cutting tool.

\subsection{Effect of cutting parameters on cutting tool life under various coolant approaches}

Figure 5a shows that at a cutting speed of 12.5 $\mathrm{m} / \mathrm{min}$ and feed rate of $0.05 \mathrm{rev} / \mathrm{min}$, dry cutting approach produced the shortest tool life, which was less than 9 min. MQNL approach achieved the longest cutting tool life by more than $40 \mathrm{~min}$. When comparing various coolant approaches to dry coolant approach, the cutting tool life improvements for MQL, MQNL, and MQNL vortex were $74.8 \%, 78.5 \%$, and $75.2 \%$, respectively. Comparing between MQNL and MQL, the cutting tool life for MQNL has improved by $14.9 \%$, while between MQNL vortex and MQL, the cutting tool life for MQNL vortex has a marginal improvement of $1.8 \%$. At this cutting speed, MQNL vortex is less effective probably due to the accumulation of chips which blocked the chilled air from reaching the cutting zone. It is worth noting that the cutting tool life for MQNL was determined to be $13.3 \%$ higher than that of MQNL vortex. 


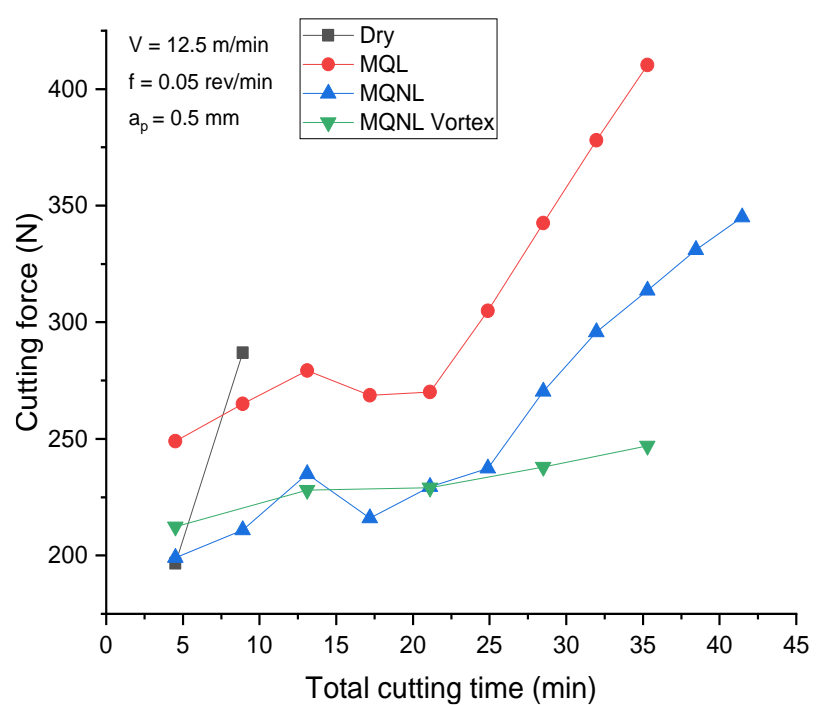

(a)

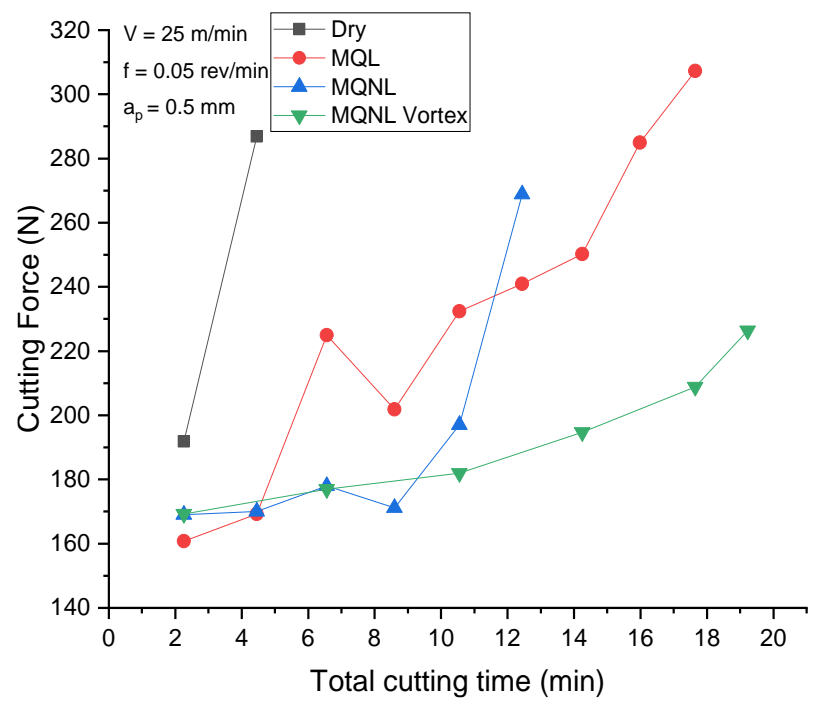

(c)

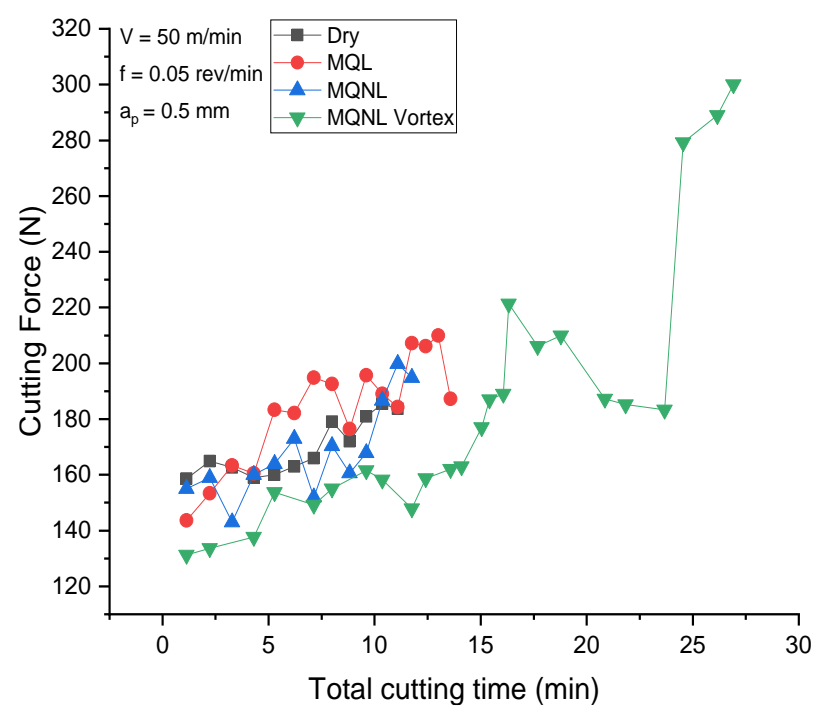

(e)

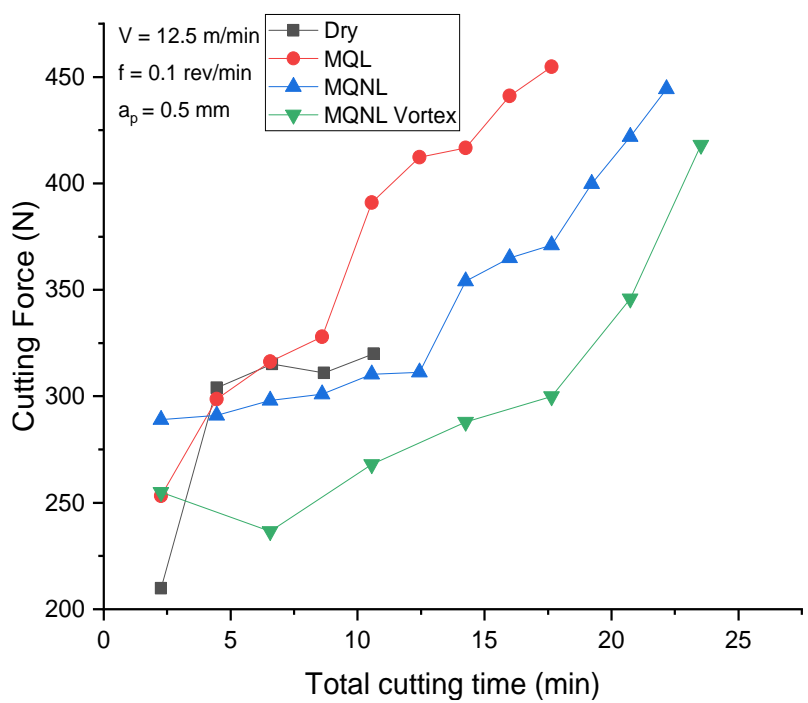

(b)

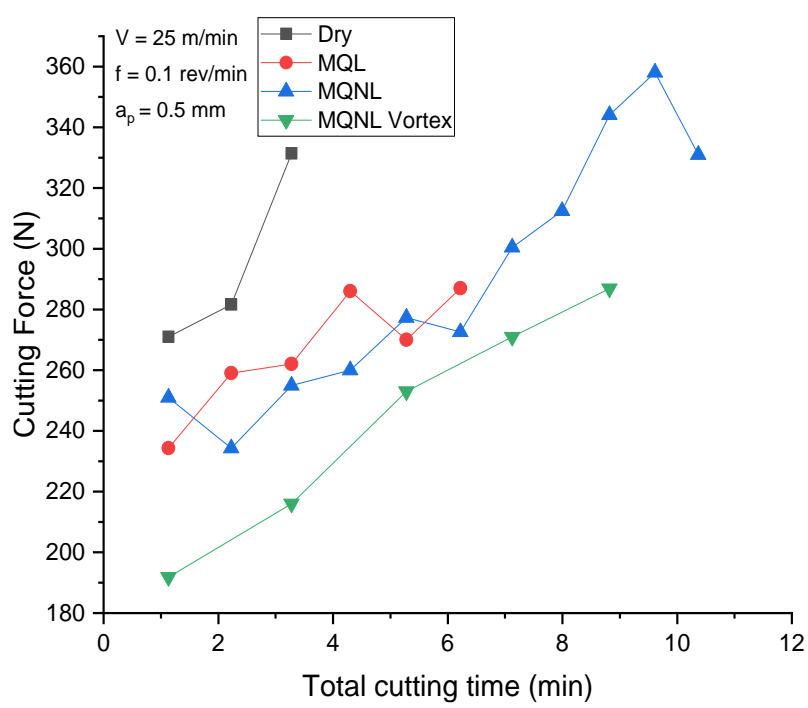

(d)

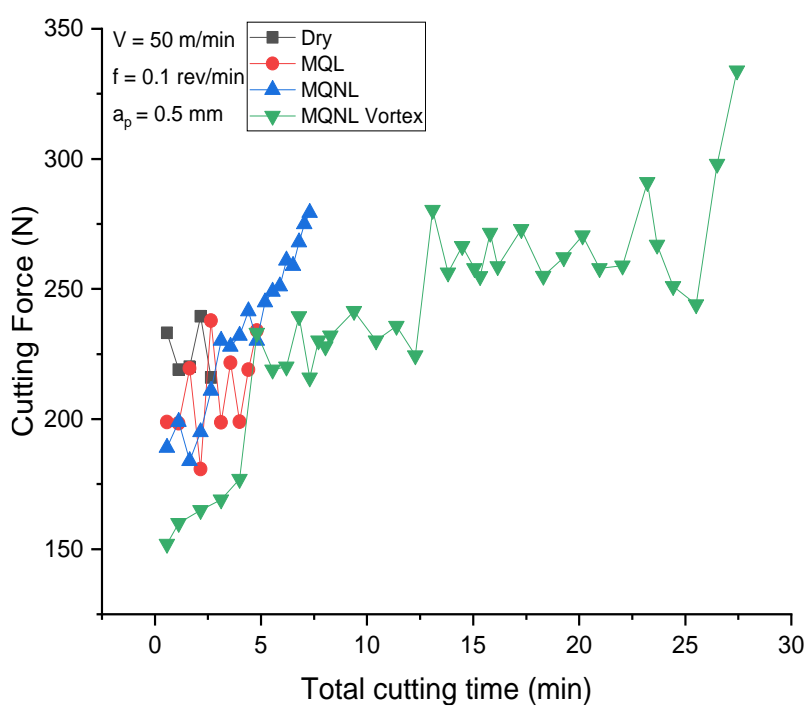

(f)

Fig. 4. Result of cutting force versus total cutting time under different cutting parameters and coolant approaches (cutting speeds (V): 12.5, 25, and $50 \mathrm{~m} / \mathrm{min}$, feed rates (f): 0.05 and $0.1 \mathrm{rev} / \mathrm{min}$, and ap $=0.5 \mathrm{~mm}$ ). 


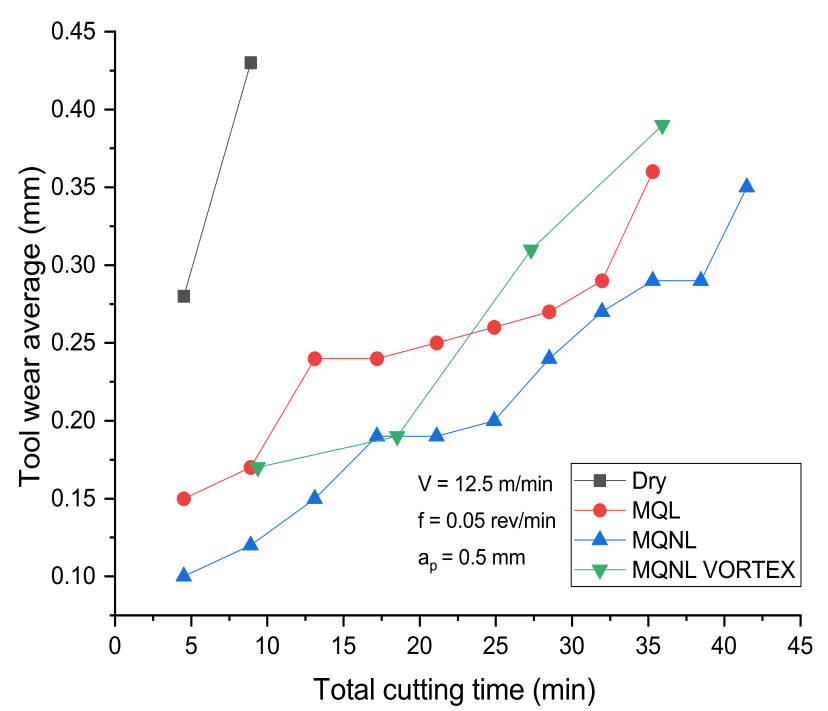

(a)

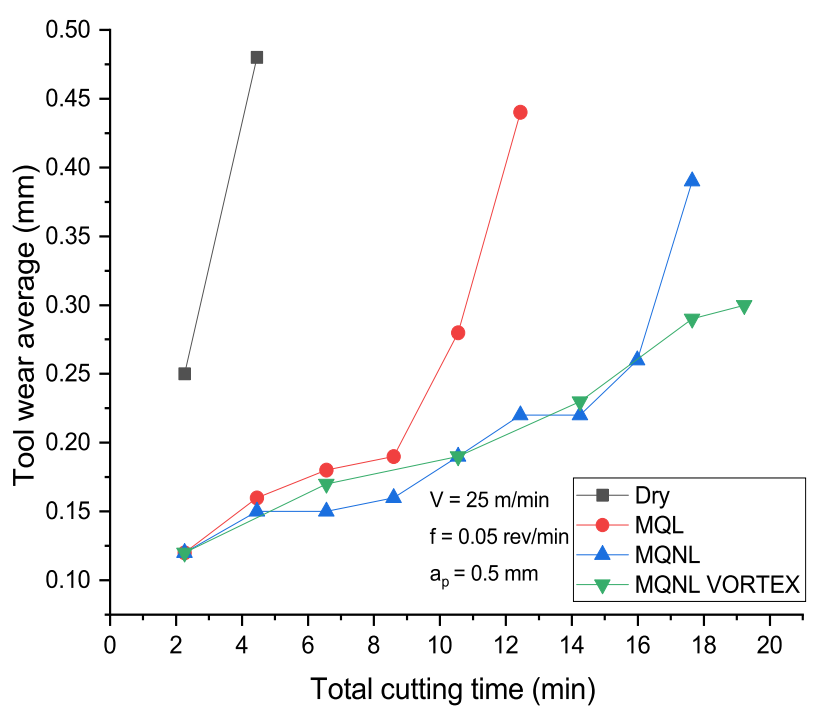

(c)

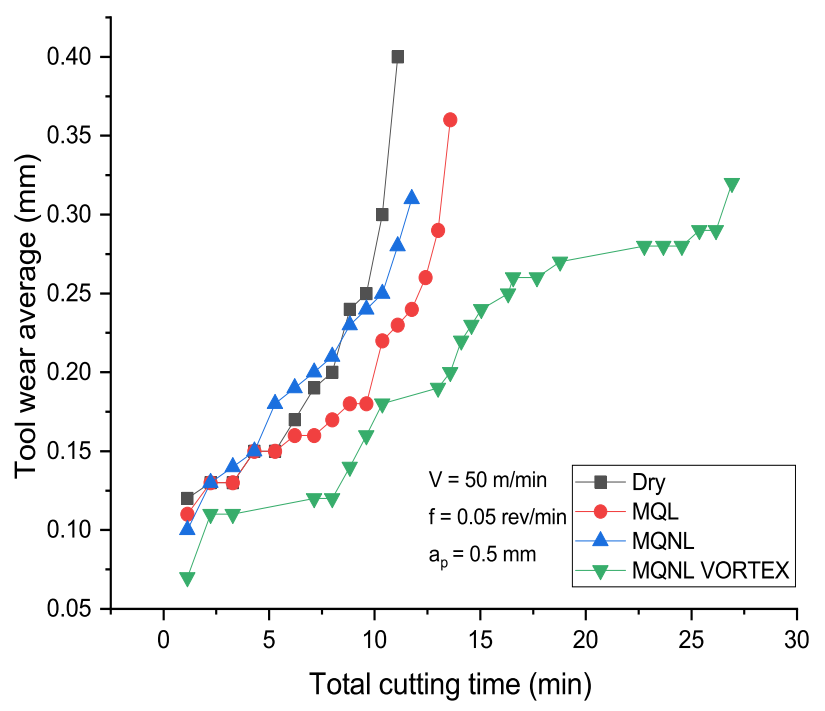

(e)

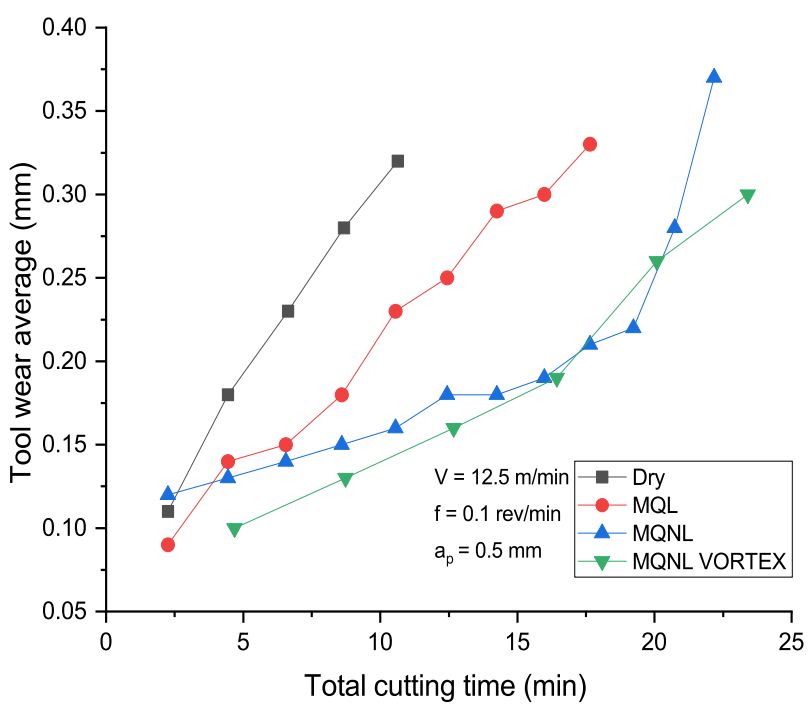

(b)

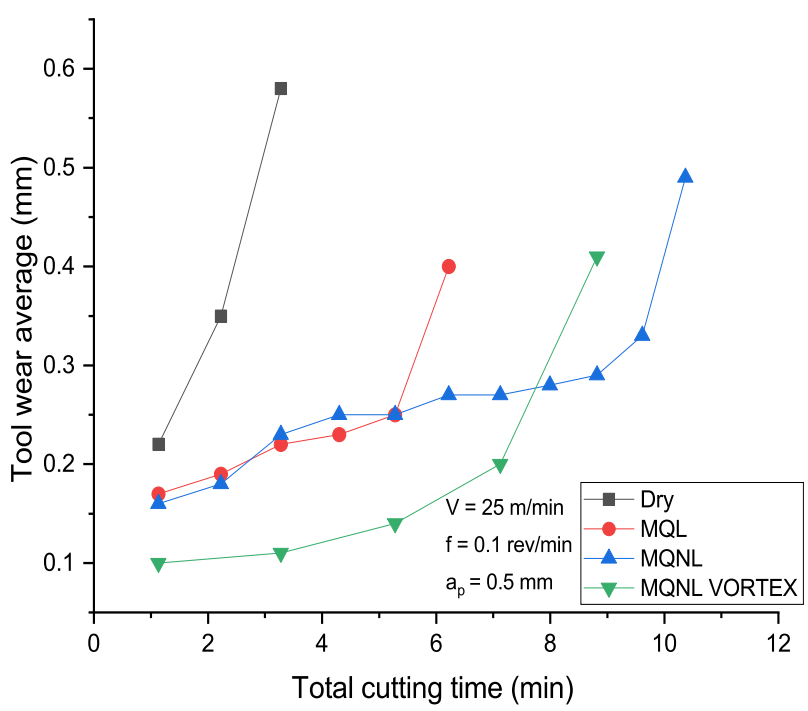

(d)

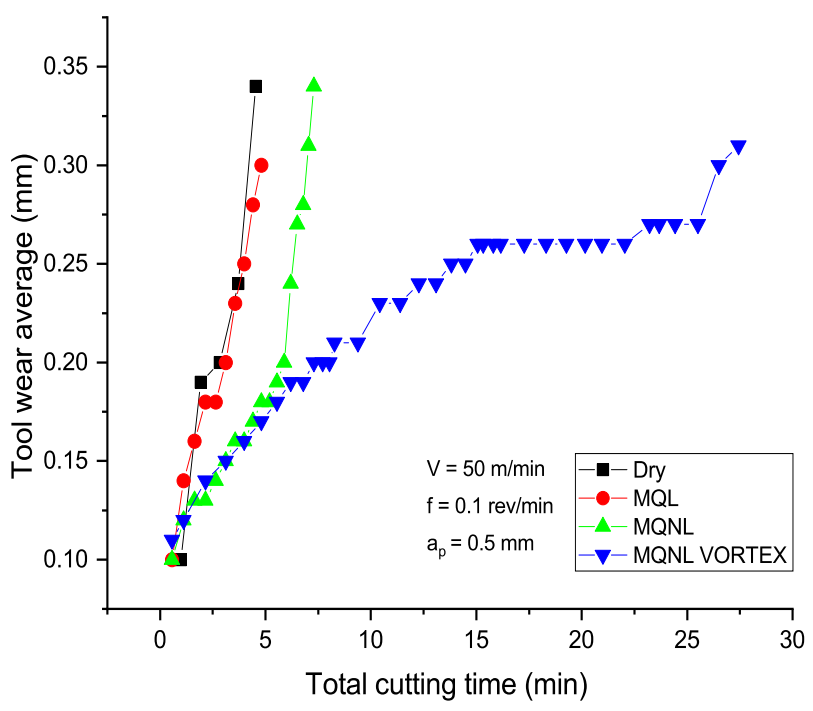

(f)

Fig. 5. Result of average tool wear versus total cutting time under different cutting parameters and coolant approaches $(\mathrm{V}=12.5,25$, and $50 \mathrm{~m} / \mathrm{min}, \mathrm{f}=0.05$ and $0.1 \mathrm{rev} / \mathrm{min}$, and ap $=0.5 \mathrm{~mm})$. 
At the cutting speed of $12.5 \mathrm{~m} / \mathrm{min}$ and a feed rate of $0.1 \mathrm{rev} / \mathrm{min}$ (Figure 5b), dry cutting approaches also had the lowest cutting tool life due to high values cutting force acting on the tool edge, and poor heat transfer in the machining zone. The MQL, MQNL, and MQNL vortex approaches showed cutting tool life improvements of $39.7 \%, 52 \%$, and $54.6 \%$, respectively compared with dry cutting. However, the MQNL approach showed a cutting tool life improvement of $20.4 \%$ compared with MQL. The MQNL vortex showed a cutting tool life improvement of $24.6 \%$ compared with MQL and a $5.3 \%$ improvement compared with MQNL. Reduction in tool-workpiece interface temperature leads to minimisation of chemical and physical reactions and hence provides a longer tool life [33].

Meanwhile, Figure $5 c$ shows that when the cutting speed was increased to $25 \mathrm{~m} / \mathrm{min}$ with a feed rate of $0.05 \mathrm{rev} / \mathrm{min}$, the dry cutting approach exhibited the lowest cutting tool life of less than $5 \mathrm{~min}$ as expected. Compared with the dry cutting approach, other coolant approaches of MQL, MQNL, and MQNL vortex showed an improvement of $64.2 \%, 74.8 \%$ and $76.9 \%$, respectively, in the cutting tool life. Likewise, MQNL vortex and MQNL increased the cutting tool life by $29.5 \%$ and $35.3 \%$, respectively, compared with MQL. MQNL vortex has slightly improved the cutting tool life by $8.2 \%$ compared to MQNL. Under the cutting speed of $25 \mathrm{~m} / \mathrm{min}$ and an increase of $0.1 \mathrm{rev} / \mathrm{min}$ in the feed rate, the dry cutting approach only sustained for a total cutting time of $3 \mathrm{~min}$, as shown in Figure $5 \mathrm{~d}$. The MQNL approach has the highest cutting time (tool life), which is $68.4 \%, 40 \%$ and $17.5 \%$, longer compared with dry cutting, MQL, and MQNL vortex approaches, respectively. It is evident that MQNL vortex was not really affective probably due to the cooling temperature achieved by the vortex tube has not reached the desired temperature of $-12{ }^{\circ} \mathrm{C}$. Additionally, air pressure form compressed supplied from compressor is probably inconsistent, thus cannot maintain the intended pressure and cause the generated cool air did not sustain at desired temperature. However, MQL and MQNL vortex approaches show improvements of $47.3 \%$, and $62.8 \%$ respectively, in the cutting tool life compared with the dry cutting approach.
At a highest cutting speed of $50 \mathrm{~m} / \mathrm{min}$ and a feed rate of $0.05 \mathrm{rev} / \mathrm{min}$ MQNL vortex showed promising improvements in the cutting tool life compared with MQNL, MQL, and dry cutting approaches by $56.3 \%, 49.6 \%$, and $58.8 \%$, respectively, as shown in Figure $5 \mathrm{e}$ and $5 \mathrm{f}$. However, MQL shows better results for cutting tool life compared with MQNL and dry cutting by $13.3 \%$ and $18.3 \%$, respectively; only a slight improvement of $5.8 \%$ is observed in the MQNL approach compared with the dry cutting approach. Finally, MQNL vortex shows significant improvements in the cutting tool life compared with dry cutting, MQL, and MQNL by $73.2 \%$, $82.3 \%$, and $83.4 \%$, respectively, at an increased feed rate of $0.1 \mathrm{~mm} / \mathrm{rev}$ and similar cutting speed of $50 \mathrm{~m} / \mathrm{min}$ (Figure 5f). Under these cutting conditions, compared with MQL and MQNL, dry cutting approach shows a $34.1 \%$ and $37.9 \%$ longer cutting tool life, respectively. MQNL does not show an improvement and is $5.7 \%$ less than that of MQL.

\subsection{Tool wear mechanism under different coolant approaches and cutting parameters}

Figure 6 depicts various conditions of wear on the tool flank face under the employed coolantlubricant approaches and cutting parameters. Abrasion dominates the wear mechanism in all conditions. The abrasion wear is visible as multiple, deep scratches on the insert's flank face. Extreme hardness of this alloy is the main factor for this abrasive wear as the chip sliding along the tool face [23], whereas the rubbing of tool against the workpiece attributed to the loss of the cutting edge and geometrical variation in the workpiece. With the increased in cutting speeds and feed rates, a hard and rough pattern is visible on the cutting tools, especially for the dry conditions. Deep grooves on the flank surface and depth of the cut boundary region can be observed.

The formation of a built-up-edge was also observed on the cutting tools under certain cutting conditions. The built-up-edge occurs due to the mechanical adhesion force at the toolworkpiece interface and causes the chip to weld to the cutting edge. Figure 7 shows the result of the energy dispersive $\mathrm{x}$-ray analysis performed at the point of the flank tool under various coolant conditions. 
DRY

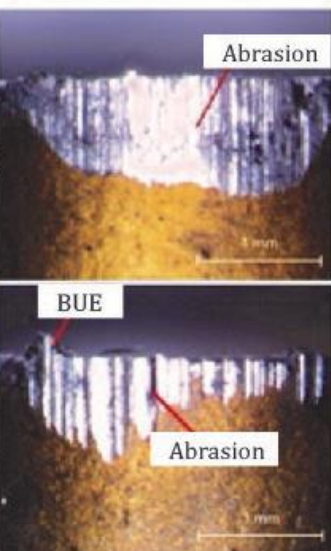

$\mathrm{V}=12.5 \mathrm{~m} / \mathrm{min}$

$\mathrm{f}=0.1 \mathrm{rev} / \mathrm{min}$

$\mathrm{V}=12.5 \mathrm{~m} / \mathrm{min}$

$\mathrm{f}=0.05 \mathrm{rev} / \mathrm{min}$

$25 \mathrm{~m} / \mathrm{min}$ $\mathrm{f}=0.05 \mathrm{rev} / \mathrm{min}$

$\mathrm{V}=25 \mathrm{~m} / \mathrm{min}$ $\mathrm{f}=0.1 \mathrm{v} \mathrm{rev} / \mathrm{min}$

$=50 \mathrm{~m} / \mathrm{min}$ $\mathrm{f}=0.05 \mathrm{rev} / \mathrm{min}$
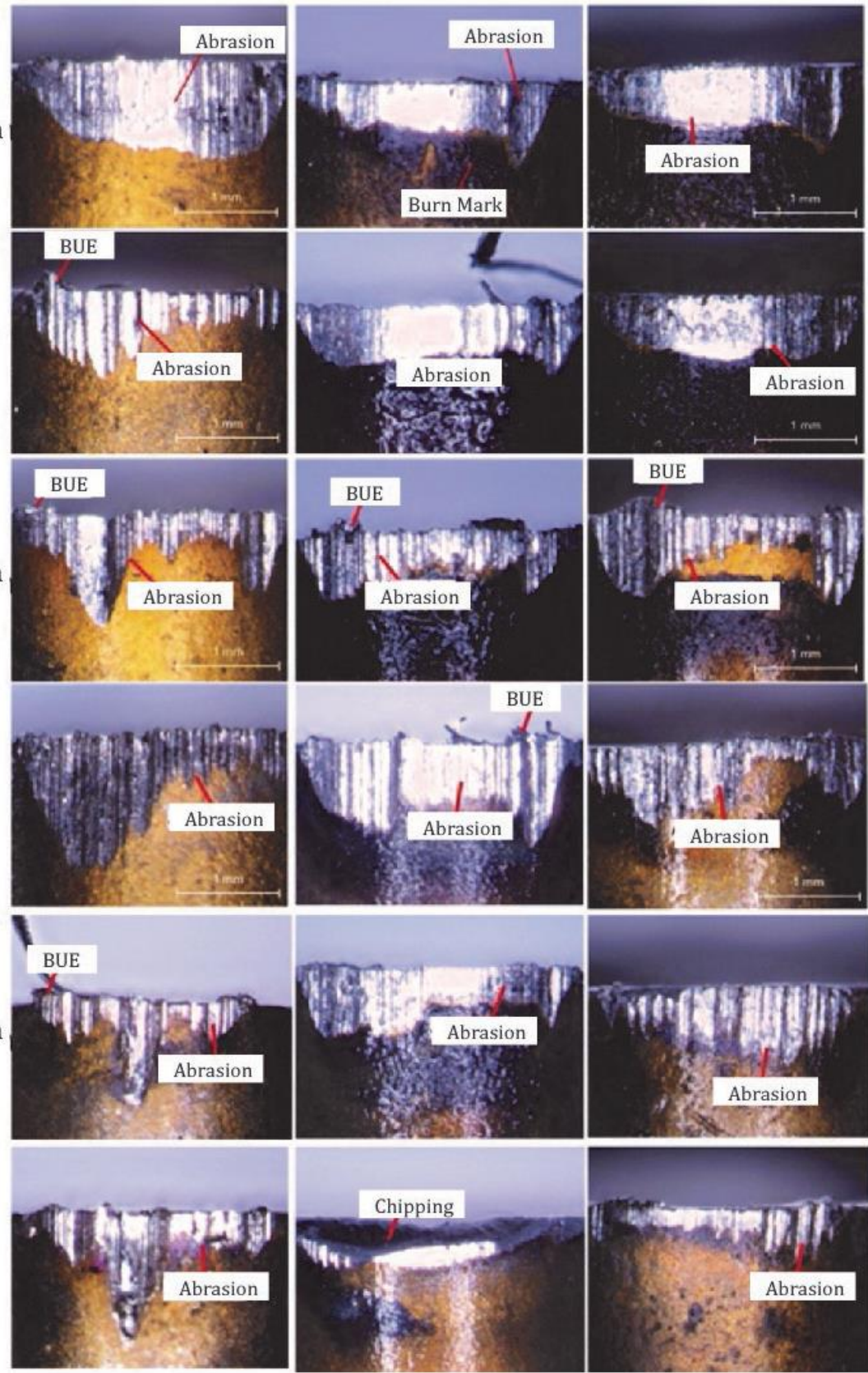
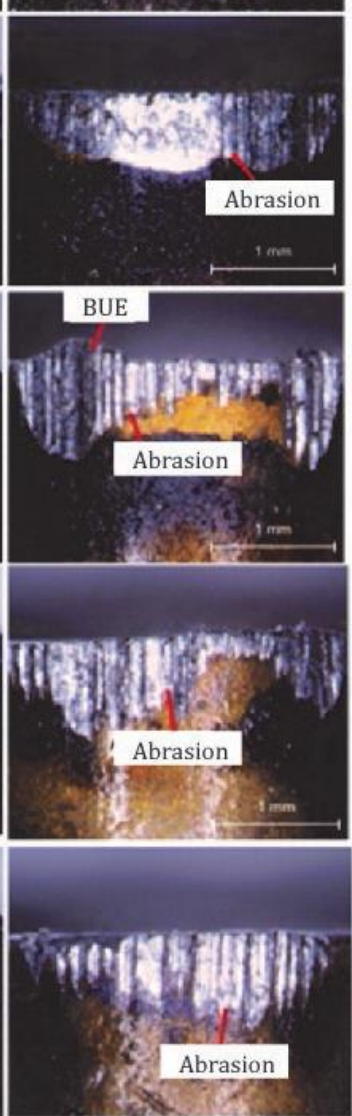

MQNL VORTEX
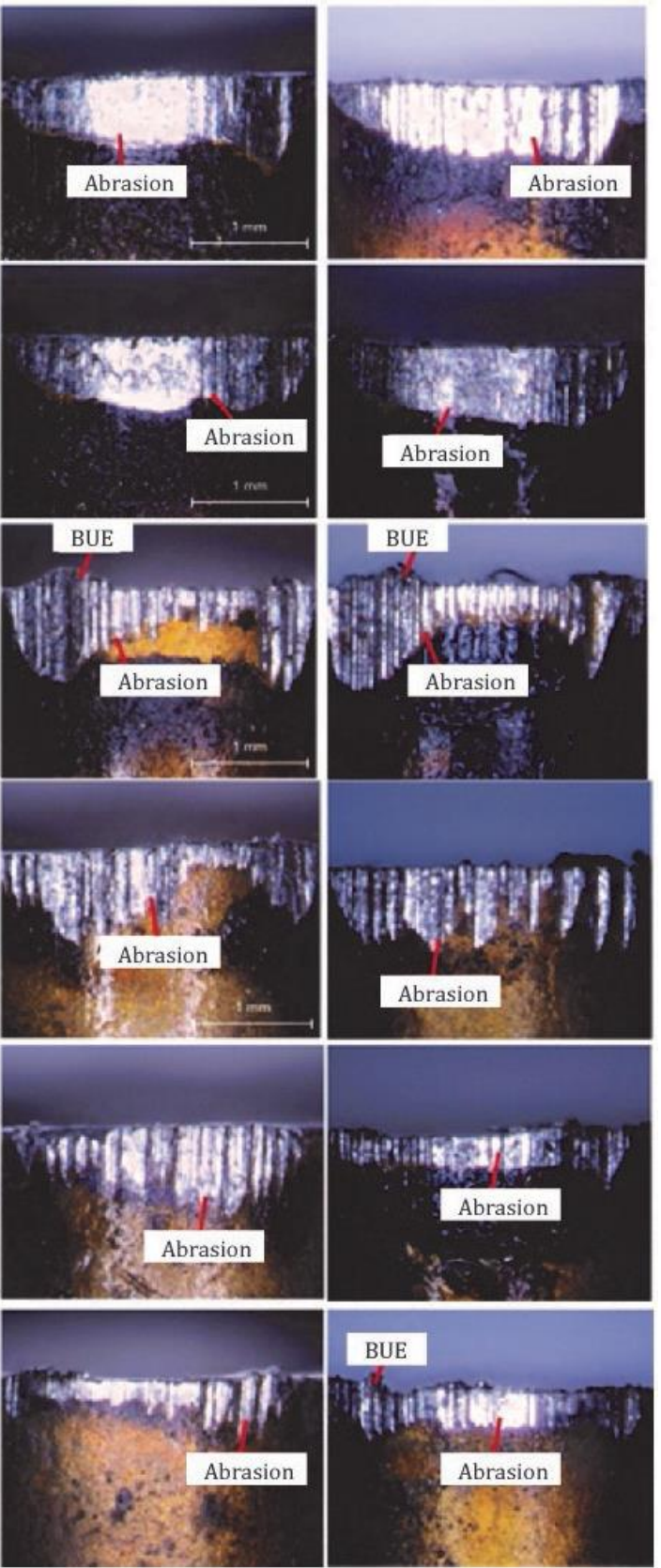

Fig. 6. Tool flank wear image under various coolant approaches and various cutting parameters $(\mathrm{V}=12.5,25$, and $50 \mathrm{~m} / \mathrm{min} ; \mathrm{f}=0.05$ and $0.1 \mathrm{rev} / \mathrm{min}$ ).

The purpose of an energy dispersive x-ray analysis was to confirm any adhesion mechanism based on the presence of elements on the cutting tool. These elemental analyses indicated the presence of $\mathrm{Ti}, \mathrm{Ni}$, and $\mathrm{Al}$ on the cutting tools, which confirmed the occurrence of adhesion wear. These two common tool wear mechanisms, namely abrasion and adhesion, were also observed in previous studies on NiTi machining $[16,24]$. The chip flowed on the tool surface during cutting process. The contact between the beneath-surface of the chip and the tool coating also caused the coating abrasion [39].
Hence, the condition for the formation of the adhering layer was facilitated with the abrasion of the tool coating. The scratches on the adhered layer were in the direction of the chip flow. Chipping or tool fracture at the edge of the cutting insert was evidenced at a higher cutting speed of $50 \mathrm{~m} / \mathrm{min}$ and a feed rate of $0.1 \mathrm{rev} / \mathrm{min}$ under the MQL approach. Tool fracture is highly correlated to attrition wear (the removal of tool material grains formed by the work material, which produces a rough area) and was caused by thermal cracking at high temperatures. In addition, the adhesion of the 
workpiece material also caused a built-up-edge, which led to tool chipping [35]. In conclusion, hybrid cooling was found to be effective in controlling the tool wear rate compared with the other coolant-lubricant approaches, which was also observed by Gupta et al. [18].

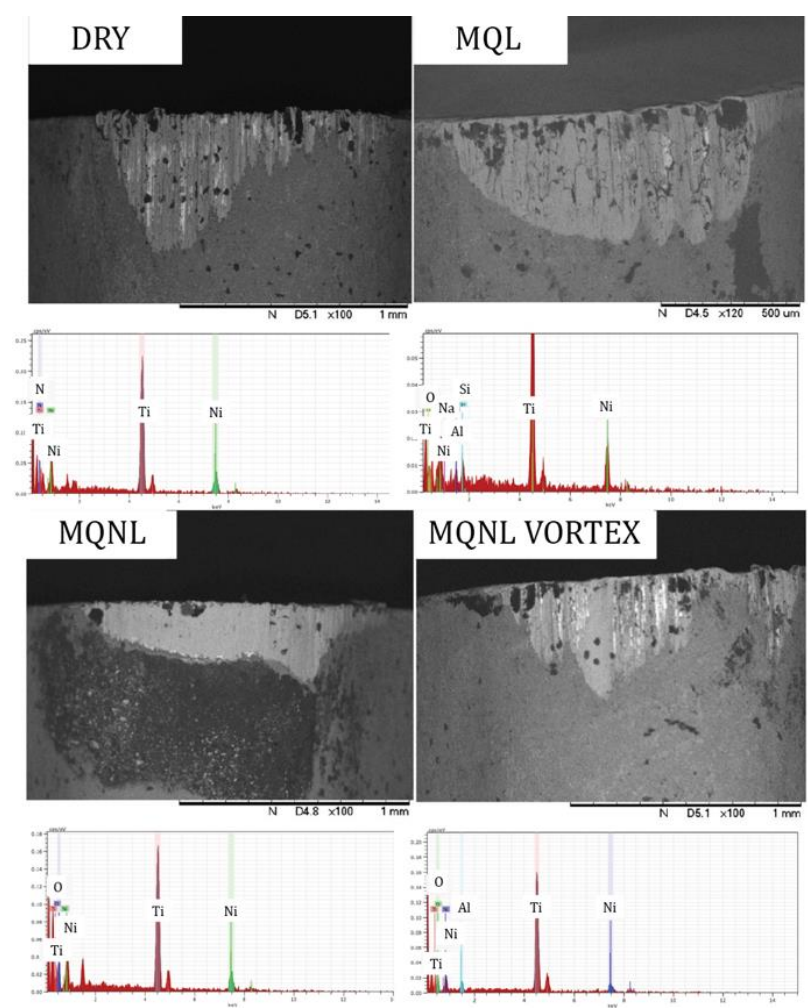

Fig. 7. The results of the energy dispersive $x$-ray analysis performed at the point of the flank tool under various coolant conditions.

\subsection{Effect of different coolant approaches and cutting parameters on surface roughness}

Figure 8 shows the average surface roughness for different cooling approaches within the employed cutting parameters. As expected, the dry cutting approach produces poor surface roughness on the surface machined of NiTi alloys. Other researchers also concluded that dry cutting of NiTi alloys produced poor machinability and surface finish because of the increased tool wear [26,27]. Compared with dry cutting, the MQL coolant approach has a better surface roughness of 20$26 \%, 11 \%$, and 5-6\%. Comparison between the dry cutting and the MQL approach, the MQNL approach showed a considerable improvement of $65 \%$, 49$52 \%$, and $6-12 \%$ in the surface roughness values. The MQNL approach improved the lubrication effect, which resulted in better heat dissipation between the cutting tool and workpiece. Similar variations in surface roughness were reported by
Ali et al. [7], Singh et al. [37], and Sharma et al. [38]. Compared to the dry and MQL approaches, the MQNL with vortex cooling approach also improves surface roughness by $8-27 \%, 8-37 \%$, and $4-9 \%$. However, the MQNL vortex cooling approach showed an improvement of only 3\% compared with the MQNL approach at a cutting speed of 50 $\mathrm{m} / \mathrm{min}$ and feed rate of $0.1 \mathrm{rev} / \mathrm{min}$.

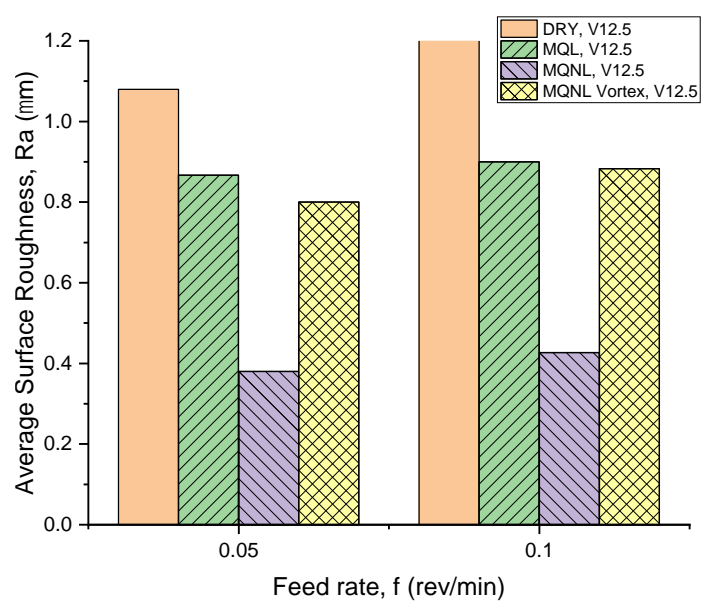

(a)

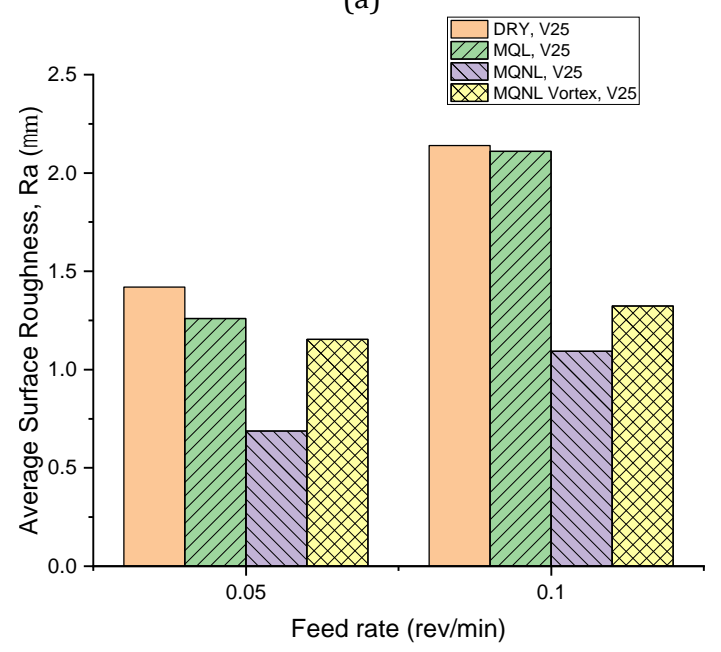

(b)

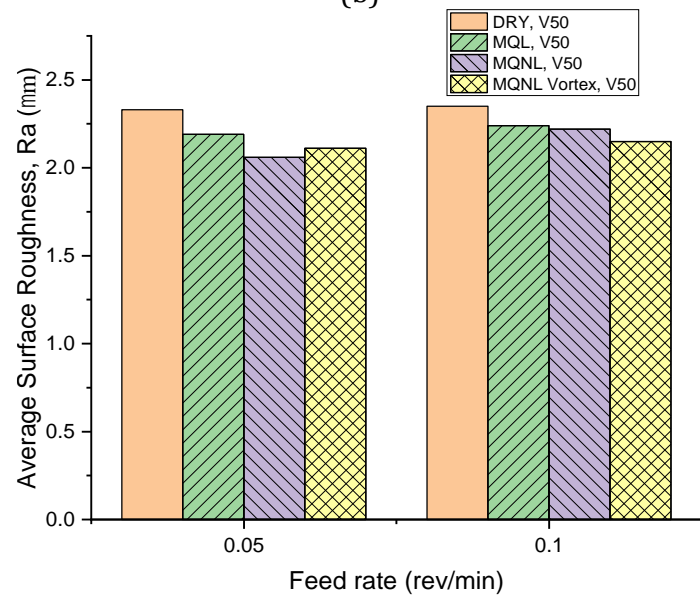

(c)

Fig. 8. Result of surface roughness for different coolant conditions and cutting parameters 


\subsection{Effect of different coolant approaches on the phase transformation (DSC Analysis)}

Figure 9 shows the results of phase transformation of generated chips under various cooling approach, namely; dry, MQL, MQNL and MQNL vortex at original state and after machining process. Chips generated from machining process under various coolant approach are analysed by using DSC analyses. It is shows substantial difference compared to original phase transformation state. The phase transformation under different coolant approaches implies severe plastic deformation of the austenite and martensite, which affects the microstructure of the material, affecting the phase transformation behaviour of the material. Thus, evidence suggests that MQNL and MQNL vortex change in structure of the work piece and alter the phase transformation during machining compared to original phase transformation state, which result in an increase in both the force components during machining and ultimately tool wear These phenomena condition also significant with the work done by Kaynak et al $[4,12]$.

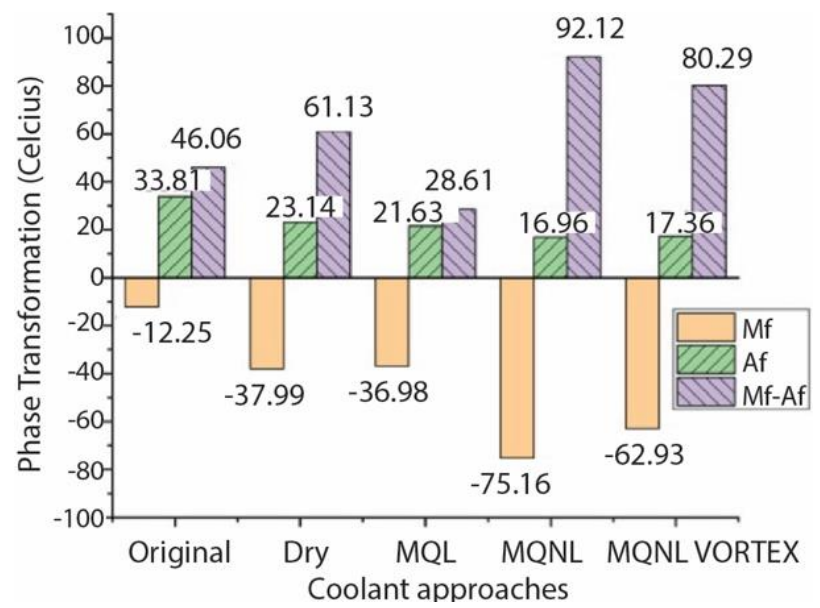

Fig. 9. Result of phase transformation under different coolant conditions before and after machining process

\section{CONCLUSION}

Based on the investigations of the turning process for NiTi alloys under various cooling approaches, this study successfully evaluated the effects of hybrid cooling and lubricating strategies on machining force development, tool wear resistance and surface roughness. From this study, a new technique of MQNL vortex that combined the coolant and lubricating functions was found effective in machining of NiTi SMAs.
The following conclusions can be made from this study:

- The MQNL and MQNL vortex approaches significantly improved the machinability of the NiTi SMA F2063 during the turning operation. These methods produced better cooling and lubrication effects during the machining process.

- The results demonstrate that the MQNL vortex approach is a new alternative method that can improve the machinability of NiTi alloys as it can reduce the cutting force, tool wear, and prolong the cutting tool life.

- Observations of flank tool wear revealed that abrasion was the dominant wear mechanism.

- Surface quality improved while using the MQNL approach. It produced a better surface compared with other cooling approaches and imparted better lubrication effects during the machining of NiTi alloys.

- The results indicate that the hybrid cooling approaches of MQNL and MQNL vortex can be better an alternative cooling approach for cleaner and sustainable manufacturing, particularly for hard-to-cut materials and unique SMAs. Moreover, these hybrid cooling approaches can achieve clean, healthy, and pollution-free machining processes.

- Finally, MQNL and MQNL Vortex cooling approaches can potentially reduce the cost of cutting tools up to $20 \%$ in terms of cutting tool life in the long run of machining process. Also, it also benefited to environment in which the cost of waste disposal by environmental agency can be reduced substantially. However, the cost of preparation of nanolubricant can be expensive at the initial stage, and the use of nanolubricant during machining process is very minimal compared to normal MQL.

\section{Acknowledgement}

The financial support was from Malaysian Ministry of Education through Fundamental Research Grant Scheme (FRGS) no: FRGS/1/2015/TK03/UNIMAP/02/6 (UniMAP Project Code: 9003-00538). 


\section{REFERENCES}

[1] M. Osama, A. Singh, R. Walvekar, M. Khalid, T. C. S.M. Gupta, W.W. Yin, Recent developments and performance review of metal working fluids. Tribology International., vol. 114, pp. 389-401, 2017, doi: 10.1016/j.triboint.2017.04.050

[2] A.P. Markopoulos, I.S. Pressas, D.E. Manolakos, $A$ review on the machining of nickel-titanium shapememory alloy, Review on Advanced Materials Science, vol. 42, pp. 28-35, 2015

[3] M.K. Sinha, R. Madarkar, S. Ghosh, P.V. Rao, Application of eco-friendly nanofluids during grinding of Inconel 718 through small quantity lubrication, Journal of Cleaner Production, vol. 141, pp. 1359-1375, 2017, doi: 10.1016/j.jclepro.2016.09.212

[4] Y. Kaynak, S.W. Robertson, H.E. Karaca, I.S. Jawahir, Progressive tool-wear in machining of room-temperature austenitic NiTi alloys: The influence of cooling/lubricating, melting, and heat treatment conditions, Journal of Materials Processing Technology, vol. 215, pp. 71-78. 2015, doi: 10.1016/j.jmatprotec.2014.07.015

[5] Ç.V. Yıldırım, T. Kıvak, M. Sarıkaya, F. Erzincanlı, Determination of MQL Parameters Contributing to Sustainable Machining in the Milling of NickelBase Superalloy Waspaloy, Arabian Journal for Science and Engineering, vol. 42, pp. 4667-4681, 2017, doi: 10.1007/s13369-017-2594-z

[6] C. Mao, Y. Huang, X. Zhou, H. Gan, J. Zhang, Z. Zhou, The tribological properties of nanofluid used in minimum quantity lubrication grinding, International Journal of Advanced Manufacturing Technology, vol. 71, pp. 12211228, 2014, doi: 10.1007/s00170-013-5576-7

[7] M.A. Mahboob Ali, A.I. Azmi, A.N. Mohd Khalil, K.W. Leong, Experimental study on minimal nanolubrication with surfactant in the turning of titanium alloys, International Journal of Advanced Manufacturing Technology, vol. 92, pp. 117-127, 2017, doi: 10.1007/s00170-017-0133-4

[8] Y.S. Dambatta, M. Sayuti, A.A.D. Sarhan, M. Hamdi, Comparative study on the performance of the MQL nanolubricant and conventional flood lubrication techniques during grinding of Si3N4 ceramic, International Journal of Advanced Manufacturing Technology, vol. 9-12, pp. 39593976, 2018, doi: 10.1007/s00170-018-1689-3

[9] Ç.V. Yıldırım, M. Sarıkaya, T. Kıvak, Ş. Şirin, The effect of addition of hBN nanoparticles to nanofluid$M Q L$ on tool wear patterns, tool life, roughness and temperature in turning of Ni-based Inconel 625, Tribology International, vol. 134, pp. 443-456, 2019, doi: 10.1016/j.triboint.2019.02.027
[10] B. Boswell, M.N. Islam, I.J. Davies, Y.R. Ginting, A. K. Ong, A review identifying the effectiveness of minimum quantity lubrication (MQL) during conventional machining, International Journal of Advanced Manufactring Technology, vol. 92, pp. 321-340, 2017, doi: 10.1007/s00170-017-0142-3

[11] A.N.M. Khalil, A.I. Azmi, M.N. Murad, A.F. Annuar, M.A.M. Ali, Coupled effects of vortex tube hybrid cooling with minimal quantity reinforced nanoparticle lubricants in turning NiTi alloys, International Journal of Advanced Manufacturing Technology, vol. 105: pp. 30073015, 2019, doi: 10.1007/s00170-019-04507-2

[12] Y. Kaynak, H. Tobe, R.D. Noebe, H.E. Karaca, I.S. Jawahir, The effects of machining on the microstructure and transformation behavior of NiTi Alloy, Scripta Materialia, vol. 74, pp. 60-63, 2014, doi: 10.1016/j.scriptamat.2013.10.023

[13] M.S. Najiha, M.M. Rahman, A.R. Yusoff, Environmental impacts and hazards associated with metal working fluids and recent advances in the sustainable systems: A review, Renewable and Sustainable Energy Reviews, vol. 60, pp. 10081031, 2016, doi: 10.1016/j.rser.2016.01.065

[14] M. Mia, Multi-response optimization of end milling parameters under through-tool cryogenic cooling condition, Measurement: Journal of International Measurement Confederation, vol. 111, pp. 134-145, 2017, doi: 10.1016/j.measurement.2017.07.033

[15] M. Jamil, A.M. Khan, H. Hegab, L.Gong, M. Mia, M. K. Gupta, Effects of hybrid $\mathrm{Al}_{2} \mathrm{O}_{3}-\mathrm{CNT}$ nanofluids and cryogenic cooling on machining of Ti - 6Al$4 \mathrm{~V}$, The International Journal of Advanced Manufacturing Technology, vol. 102, pp. 38953909, 2019, doi: 10.1007/s00170-019-03485-9

[16] M. Mia, N.R. Dhar, Influence of single and dual cryogenic jets on machinability characteristics in turning of Ti-6Al-4V, Proceedings of Institution of Mechanical Engineers: Part B Journal of Engineering Manufacture, vol. 233, iss. 3, pp. 711726, 2019, doi: 10.1177/0954405417737581

[17] W. Zhao, L. Gong, F. Ren, L. Li, Q. Xu, A.M. Khan, Experimental study on chip deformation of Ti-6Al$4 \mathrm{~V}$ titanium alloy in cryogenic cutting, International Journal of Advanced Manufacturing Technology, vol. 96, pp. 40214027, 2018, doi: 10.1007/s00170-018-1890-4

[18] M.K. Gupta, M. Mia, G.R. Singh, D.Y. Pimenov, M. Sarikaya, V.S. Sharma, Hybrid cooling-lubrication strategies to improve surface topography and tool wear in sustainable turning of Al 7075-T6 alloy, International Journal of Advanced Manufacturing Technology, vol. 101, pp. 55-69, 2018, doi: 10.1007/s00170-018-2870-4 
[19] F. Rabiei, A.R. Rahimi, M.J. Hadad, Performance improvement of eco-friendly MQL technique by using hybrid nanofluid and ultrasonic-assisted grinding, The International Journal of Advanced Manufacturing Technology, vol. 93, pp. 10011015, 2017, doi: 10.1007/s00170-017-0521-9

[20] W. Stachurski, J. Sawicki, R. Wójcik, K. Nadolny, Influence of application of hybrid MQL-CCA method of applying coolant during hob cutter sharpening on cutting blade surface condition, Journal of Cleaner Production, vol. 171, pp. 892910, 2018, doi: 10.1016/j.jclepro.2017.10.059

[21] G.A. Porter, P.K. Liaw, T.N. Tiegs, K.H. Wu, Fatigue and fracture behavior of nickel-titanium shapememory alloy reinforced aluminum composites, Material Science Engineering: A, vol. 314, iss. 12, pp. 186-193, 2001, doi: 10.1016/S09215093(00)01915-8

[22] Y. Kaynak, H.E. Karaca, R.D. Noebe, I.S. Jawahir, Analysis of tool-wear and cutting force components in dry, preheated, and cryogenic machining of NiTi shape memory alloys, in Procedia CIRP, vol. 8, pp. 498-503, 2013, doi: 10.1016/j.procir.2013.06.140

[23] A.N.M. Khalil, A.I. Azmi, M.N. Murad, M.A. Mahboob Ali, The effect of cutting parameters on cutting force and tool wear in machining Nickel Titanium Shape Memory Alloy ASTM F2063 under Minimum Quantity Nanolubricant, Procedia CIRP, vol. 77, pp. 227-230, 2018, doi: 10.1016/j.procir.2018.09.002

[24] M. Mia, G.R. Singh, M.K. Gupta, V.S. Sharma, Influence of Ranque-Hilsch vortex tube and nitrogen gas assisted $M Q L$ in precision turning of Al 6061-T6, Precision Engineering, vol. 53, 2017, doi: 10.1016/j.precisioneng.2018.04.011

[25] Z. Haddad, C. Abid, H.F. Oztop, A. Mataoui, A review on how the researchers prepare their nanofluids, International Journal Thermal Science, vol. 76, pp. 168-189, 2014, doi: 10.1016/j.ijthermalsci.2013.08.010

[26] A.N.M. Khalil, M.A.M. Ali, A.I. Azmi, Effect of Al2O3 Nanolubricant with SDBS on Tool Wear During Turning Process of AISI 1050 with Minimal Quantity Lubricant, Procedia Manufacturing, vol. 2, pp. 130134, 2015, doi: 10.1016/j.promfg.2015.07.023

[27] A. Gok, A new approach to minimization of the surface roughness and cutting force via fuzzy TOPSIS, multi-objective grey design and RSA, Measurement, vol. 70, pp. 100-109, 2015, doi: 10.1016/j.measurement.2015.03.037

[28] A. Gök, K. Gök, M.B. Bilgin, M.A. Alkan, Effects of cutting parameters and tool-path strategies on tool acceleration in ball-end milling, Material Tehnology, vol. 51, pp. 957-965, 2017, doi: 10.17222/mit.2017.039

[29] B. Sen, M. Mia, U.K. Mandal, S.P. Mondal, Synergistic effect of silica and pure palm oil on the machining performances of Inconel 690: A study for promoting minimum quantity nano doped-green lubricants, Journal Cleaner Production, vol. 258, pp. 120755, 2020, doi: 10.1016/j.jclepro.2020.120755

[30] S.H. Musavi, B. Davoodi, S.A. Niknam, Effects of reinforced nanoparticles with surfactant on surface quality and chip formation morphology in MQL-turning of superalloys, Journal of Manufacturing Processes., vol. 40, pp. 128-139, 2019, doi: 10.1016/j.jmapro.2019.03.014

[31] S.S. Chaudhari, R.R. Chakule, P.S. Talmale, Experimental study of heat transfer characteristics of Al2O3 and $\mathrm{CuO}$ nanofluids for machining application, Materials Today Proceedings, vol. 18, part 3, pp. 788-797, 2019, doi: 10.1016/j.matpr.2019.06.499

[32] Chetan, S. Ghosh, P. V. Rao, Comparison between sustainable cryogenic techniques and nano-MQL cooling mode in turning of nickel-based alloy, Journal of Cleaner Production, vol. 231, pp. 10361049, 2019, doi: 10.1016/j.jclepro.2019.05.196

[33] Y. Shokoohi, E. Khosrojerdi, B.H. Rassolian Shiadhi, Machining and ecological effects of a new developed cutting fluid in combination with different cooling techniques on turning operation, Journal of Cleaner Production, vol. 94, pp. 330339, 2015, doi: 10.1016/j.jclepro.2015.01.055

[34] S. Sartori, L. Moro, A. Ghiotti, S. Bruschi, On the tool wear mechanisms in dry and cryogenic turning Additive Manufactured titanium alloys, Tribology International, vol. 105, pp. 264-273, 2016, doi: 10.1016/j.triboint.2016.09.034

[35] T. Luo, X. Wei, X. Huang, L. Huang, F. Yang, Tribological properties of Al203 nanoparticles as lubricating oil additives, Ceramic International, vol. 40, iss. 5, pp. 7143-7149, 2014, doi: $10.1016 /$ j.ceramint.2013.12.050

[36] K. Weinert, V. Petzoldt, D. Kotter, Turning and Drilling of NiTi Shape Memory Alloys, CIRP Annals. Technology, vol. 53, iss. 1-2, pp. 65-68, 2004, doi: 10.1016/j.msea.2003.10.344

[37] T. Singh, J.S. Dureja, M. Dogra, M.S. Bhatti, Environment Friendly Machining of Inconel 625 under Nano-Fluid Minimum Quantity Lubrication (NMQL), International Journal of Precision Engineering Manufacturing, vol. 19, pp. 16891697, 2018, doi: 10.1007/s12541-018-0196-7

[38] P. Sharma, B.S. Sidhu, J. Sharma, Investigation of effects of nanofluids on turning of AISI D2 steel using minimum quantity lubrication, Journal of Cleaner Production, vol. 108, pp. 72-79, 2015, doi: 10.1016/j.jclepro.2015.07.122

[39] G. Nasr, M. Soltantarzeh, B. Davoodi, A. Hajaliakbari, Assessment of tool wear mechanisms in high-pressure jet-assisted turning process of a nickel-based superalloy, Wear, vol. 460-461, pp. 1-11, 2020, doi: 10.1016/j.wear.2020.203454 